\title{
Where Is the Goal Line? A Critical Look at Police Body-Worn Camera Programs
}

\author{
Geoffrey P. Alpert \\ University of South Carolina \\ Griffith University
}

\section{Kyle McLean}

Florida State University

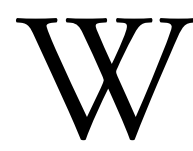

hen police were provided with dash-cam or in-car recorders, it was argued they would be able to confirm the stories officers were telling and assist with prosecutions, while capturing improper police actions. Soon after their implementation, the in-car videos along with closed-circuit television (CCTV) were being used to justify police activities, played in court to help convict criminals, and reviewed for police misconduct. These videos have been lauded for confirming proper behavior in driving-under-the-influence (DUI) enforcement, sustaining comments and actions officers attributed to subjects, and showing the dangers of high-speed pursuits, among other activities. When the first generation of cameras was rolled out in the 1980s, there was no agreed-upon goal for them, some video was grainy, cameras were not always pointing in the right direction, they were not always working, they were not always turned on, and tapes were sometimes full or damaged (International Association of Chiefs of Police [IACP], 2004). Watching the videos was, for the most part, a boring exercise. The video evidence, however, was helpful in understanding the daily routines of officers (Meyer, 2014) and helped prosecute drunk drivers. Mothers Against Drunk Driving helped convince government and private funders to purchase the equipment for law enforcement. Quickly, fears and apprehension transformed into satisfaction and support, as the videos more often than not exonerated officer behavior and in many cases reduced citizen complaints. ${ }^{1}$ In the late 1990s, there was an emphasis for agencies using the technology to develop a thorough

Direct correspondence to Geoffrey P. Alpert, Department of Criminology and Criminal Justice, University of South Carolina, Columbia, SC 29208 (e-mail: geoffa@mailbox.sc.edu).

1. Some issues needed to be evaluated, however, including the reasons for the suspension of random reviews of tapes (Eiserer, 2012). 
planning effort so in-car cameras would be successful, including provisions for storage, filing, identifying, and retrieving video evidence (IACP, 2004).

Over the past few years, history has repeated itself with similar arguments and concerns regarding on-officer cameras, known as body-worn cameras (BWC). As with the original in-car cameras, BWCs sometimes have low video quality, cameras are frequently pointing in the wrong direction, they do not always work, and officers sometimes fail to turn them on. Further reliving the past, reviewing BWC footage, as anyone who has done so can attest, is an extremely boring exercise but one that gives a valuable glimpse into the daily activities of police officers. Once again, activists and reformers have pushed for this tool to be implemented across agencies with the focus this time on reducing officer misconduct and citizen complaints, rather than on drunk driving. As BWCs have been adopted by more agencies, a new (but previous) revelation is that videos can be helpful in exonerating officers' behavior and in generating new evidence. In a final echo of the past, the Department of Justice and many academics (such as White, Todak, and Gaub, 2018, this issue) have pushed for agencies to develop a comprehensive plan for BWCs to improve implementation of the cameras.

Although the implementation of in-car cameras was easy, the rollout of BWCs has been a nightmare. The Police Executive Research Forum (PERF, 2014) raised questions about the benefits of a BWC, while discussing considerations for implementation such as training to make sure officers turned cameras on, privacy concerns (such as when, where, and what to record), storage, retention, and disclosure issues. PERF also sounded alarms that officers may have concerns with wearing a BWC, but the organization did not systematically survey or interview officers. Fortunately, research and evaluation of BWCs has exploded during the past few years after its implementation in various police agencies across the country (Developments in the Law, 2015; Jennings, Fridell, and Lynch, 2014; Jennings, Lynch, and Fridell, 2015; White, 2014). Recently, in 2017, the Los Angeles Police Department held a Body-Worn Camera Research Convening, at which time the latest research findings were presented and issues for the future were discussed. The approaches taken by the researchers were impressive as were the partnerships between researchers and agencies. One such approach is presented in an article by Michael White, Natalie Todak, and Janne Gaub (2018) in this issue. "Examining Body-Worn Camera Integration and Acceptance Among Police Officers, Citizens, and External Stakeholders" summarizes the Bureau of Justice Assistance (BJA) implementation guide (BJA, 2016) and investigates support for BWCs from officers, citizens, and stakeholders. As documented in the article, creating a comprehensive plan for implementation with all of the relevant stakeholders is necessary to gain acceptance of BWCs during implementation.

Despite the impressive wealth of quality research conducted on BWCs in a short time, several critical concerns and policy issues have yet to be addressed. Perhaps none is more critical than the simple identification of a clear goal for a BWC program. In our experience, it is common for members of the media or the general public to ask policing experts, "Do 
body-worn cameras work?" The answer is, usually, "It depends on what you want them to do." Without a clear goal for the BWC program, there is little direction for external stakeholders to assess the department's success. In turn, the incentive for line-level officers to activate their cameras is to avoid disciplinary infractions, not necessarily to capture evidence. Answers to questions from external parties and officers themselves, concerning officer adherence to policy and program success, can be difficult to answer without a clear programmatic goal. White et al. (2018) note that in the BJA (2015) checklist, communicating with stakeholders includes the critical step of publicizing the goals of the program. A critical review of the literature on BWCs, however, reveals a wide variety of assumed outcomes of BWC implementation that make the development of a clear goal a unique challenge for policy makers (see Maskaly, Donner, Jennings, Ariel, and Sutherland, 2017). We turn now to two critical issues, goals and compliance.

\section{Goals}

The rise in BWCs across the country has been plagued in part by a clear push for the technology to be implemented, but a clear or defined goal for success has been remarkably absent. Although programs such as hot-spots policing or community outreach have clear goals, such as reducing crime and improving community relations, BWC programs have no such goal. Lawmakers have pushed for there to be "a camera on every officer" in agencies throughout their jurisdictions (see Conlin, 2017; SC Code of Laws $\$$ 23-1-240). Furthermore, in jurisdictions where there is no legal mandate, public pressure, the desire to appear cutting edge, using a best practice, or the opportunity to obtain financial support through government grants can push law enforcement executives to adopt BWCs. There is also a growing body of research in which the adoption of BWCs is encouraged (which will be reviewed in greater detail later in this essay). It is unwise, however, for a law enforcement executive to get swept up in the BWC push without carefully evaluating his or her goals and policies (see White, 2014).

One of the earliest experiments on the use of BWCs in a policing agency, colloquially known as the "Rialto experiment," suggested that wearing a BWC reduced the likelihood that an officer would use force (see Farrar, 2013; also, Ariel, Farrar, and Sutherland, 2015). Reducing the use of force, especially if done while maintaining officer safety and productivity, is a key goal of many leaders in law enforcement. Other studies in which use of force was used as an outcome, however, have failed to reach the same conclusion (Ariel et al., 2016b; Yokum, Ravishankar, and Coppock, 2017). The Rialto experiment also noted significant reductions in the number of complaints filed against officers wearing BWCs (Ariel et al., 2015; Farrar, 2013). Subsequent research has provided mixed results, with some researchers supporting the finding (e.g., Grossmith et al., 2015; Jennings et al., 2015; Katz, Choate, Ready, and Nuño, 2014), and others not replicating the reductions in complaints filed against officers (e.g., Yokum et al., 2017). Even though the findings from studies demonstrate reductions (see, e.g., Maskaly et al., 2017), it is still not clear that a properly implemented BWC 
program will reduce the use of force or complaints. The issue with targeting these outcomes using a body-worn camera program is perhaps best identified in the earlier work of White, Gaub, and Todak (2017: 7) who reminded us that "the outcomes of interest are rare." In small-to-mid-sized departments, reductions in these events may be difficult to determine as there are so few incidents to measure. As such, these outcomes, although important, are not ideal for a program goal, as not achieving them may not be because of a problem with the BWC program.

Beyond use of force and complaints filed against the police, politicians and activists advocate for the use of BWCs as a method of improving transparency. Improving transparency in a police department is a procedurally fair action that may lead to greater trust in the police. The transparency goal, however, is also fraught with potential pitfalls. At times, law enforcement executives may be handicapped by state laws or investigative concerns that prevent the release of BWC video to either support or refute officers' stories. For example, a shooting in Charlotte, NC, in September 2016 saw BWCs cause a potential backfire in public relations as the police department was criticized through media headlines such as "2 Stories, Many Cameras: Protestors Demand Video of Charlotte Shooting” (Domonoske, 2016), "ACLU Calls on Police to Release Video Footage of Shooting" (Alexander, 2016), and after its release, "Video of Charlotte Police Shooting Could Be the Last Released in North Carolina" (Bromwich, 2016). In fact, the Charlotte-Mecklenburg Police Department must now obtain a court order before releasing any body-worn camera footage to the public (Wester, 2017). Although no studies have been aimed at examining whether this requirement is seen as positive or negative by community members and other stakeholders, it is unlikely that making BWC footage harder to access will make departments seem more transparent.

Unfortunately, the trouble with transparency does not end with the release of the footage. BWCs are also plagued by the same problem experienced by sports fans. Whether it is the National Football League (NFL), National Collegiate Athletic Association (NCAA), or the media, using multiple hi-definition cameras from a variety of angles, and even dynamic microphones, fans are regularly treated to confusion and a sense of injustice as video reviews of plays are inconclusive. Instant replay reviews by trained expert referees regularly have difficulty in determining a fumble, first down, penalty, or touchdown. In fact, fans and observers are still arguing over controversial plays years, if not decades, later. Police departments have fewer cameras, less precise angles, and even if BWCs were placed on every officer in every jurisdiction, there will still be outcomes that are ambiguous at best. As one Los Angeles Police Department official put it, watching BWCs is often "like watching a baseball game through a straw: you only see what you can through a narrow hole focused, for example, on the batter" (Arif Alikhan, personal correspondence, February 2018). An analysis of an event with BWC footage will likely still require additional evidence to determine whether a use of force was objectively reasonable.

As a result of concerns over the release of BWC footage and the likely shortcomings of the video to capture all that is happening in a given incident, BWCs will not be the 
silver bullet to make police departments completely transparent. In our own research, which includes reviewing a considerable number of hours of BWC footage, we often question: "What did she say?" "What happened over there?" and "I'm not sure. I wish I could see it from a different angle."

Finally, it has been argued that BWC programs improve evidentiary quality for police departments. This improvement may be the best way BWCs can improve policing and represents conceivably the clearest measure to determine the success of a BWC program. As White et al. (2018) in this issue demonstrate, there is considerable evidentiary promise to BWCs. Using a BWC can reduce the time to case disposition and the rate of guilty outcomes for a police department, which are both excellent goals for a BWC program.

\section{Compliance}

Identifying a clear goal for a BWC program is necessary to encourage officers to comply with its components. As demonstrated extensively in criminological research, individuals are more likely to engage in compliant behaviors if they are doing so because they believe it is the right thing to do, rather than to avoid punishment. Consistent with this argument, White (2014) noted in the BJA (2015) checklist that clearly articulating goals to line-level officers represents a best practice for addressing their concerns about the use of BWCs. White et al. (2018) note in this issue that in Tempe, AZ, this model was followed and that goals were clearly communicated to their officers. As a result, attitudes toward the BWC program improved. Obtaining greater support for the BWC program should lead to greater compliance with BWC policy.

Compliance with BWC policy is typically focused on whether officers activate their camera at the beginning of incidents and keep them on until the time when their policy permits shutting them off. Failure to activate and keep the camera activated can dilute the effects of the BWC program across all four goals previously discussed. Ariel and colleagues (2016a) found that the ability of BWCs to reduce use-of-force incidents could be compromised by an officer exercising discretion not to activate the camera or to turn it off too early. Similarly, cameras may not be activated when misconduct that could lead to a complaint is likely, reducing the potential impact of BWCs on complaints. If a controversial incident occurs when a camera is off, whether intentional or not, transparency is also reduced, ${ }^{2}$ and obviously, the evidentiary value of the video is lost as well. ${ }^{3}$

Compliance within a BWC program is difficult to assess even with well-defined goals. Databases of BWC videos can be searched methodically for video of a particular incident, but finding a video only means that partial compliance was achieved. The video may not

2. Another headline from the previously referenced Charlotte incident read: "Charlotte Officer did not Activate Body Camera Until After Keith Scott Had Been Shot" (Lowery, 2016).

3. It is important to note that some interactions can develop quickly and that turning on a camera can affect officer safety. 
have begun at the start of an incident (see footnote 2); may not have been recorded by all officers on the scene; or may be obscured, covered, or pointed in a different direction for critical portions of the incident. Thus, obtaining an estimate of full compliance with the BWC program requires a researcher to sit and watch videos of each incident selected to ensure that all officers on scene recorded the incident from the time they arrived on scene until policy allows them to deactivate their camera.

Further complicating these types of analyses is the understanding that full compliance for every incident is unlikely to ever be achieved. As noted in footnote 3 , incidents that begin as a condition that does not require recording (e.g., directing traffic) can escalate rapidly to an incident that requires recording (e.g., an encounter with the law-violating driver). Another example is an officer who is attacked and unable to turn on a camera. Furthermore, officers are human and make mistakes. There will likely be genuinely benign incidents where the officer simply forgets to activate his or her camera. Thus, policy makers and researchers alike are tasked with determining what level of compliance is acceptable. In other words, how close is close enough?

Despite the challenges of assessing compliance, it is an important component of a BWC program. The findings of White et al. (2018) in this issue are so important because greater support for a BWC program should translate into greater compliance. Greater compliance will then give a police department the best chance at achieving whichever goal it set out to accomplish with its BWC program.

\section{Policy Transfer}

Another potential hurdle for BWC programs in achieving identified goals is the concept of policy transfer. In a critique of randomized controlled trials (RCTs), Sampson (2010) noted that the findings of RCTs may not translate to broad, permanent policy changes. In particular, the findings of BWC studies may become compromised when the program is expanded from a carefully executed trial of a selection of officers to a mandate that all officers wear cameras. For example, a potential Hawthorne effect may be occurring because officers carrying cameras will know they are involved in a study and in the treatment group as a result of being given a camera to wear. Additionally, there is the potential that changes to officer behavior resulting from wearing a BWC will diminish over time (e.g., White et al., 2017). Embedded researchers and investigative reporters often note that even though participants are guarded toward them in the beginning of their time in a given environment, as the participants get used to their presence, their behavior often reverts back to its norm. Perhaps the changes in officer behavior seen in BWC RCTs are temporary and long-term policy changes will not have the same impact. As a result, policy makers should consider taking steps such as the regular auditing of BWC footage by supervisors who are able to coach, re-train, or discipline officers so they will understand the seriousness and importance of compliance with the BWC program. 


\section{Conclusion}

It is easy to understand the pressures that law enforcement executives are under to adopt BWC programs quickly, but a methodical, measured approach as outlined by the BJA (2015) checklist is more likely to result in a program that accomplishes its goals, satisfies external stakeholders, and obtains the support of line-level officers. Critical to this approach is the identification of measurable goals for a BWC program. As outlined here, BWCs may have the goal of reducing uses of force and complaints against officers, but these activities are rare and influenced by a variety of external factors that may result in a premature declaration of success or failure. BWCs may assist agencies in achieving a greater level of transparency, but the agency must be committed to following a clear process for the release and review of footage. Furthermore, the agency should make clear to external stakeholders that the footage will not always be conclusive and the stakeholders must be willing to accept that clear answers will not always be possible. ${ }^{4}$ Finally, BWCs show the most promise in improving the quality of evidence produced by a law enforcement agency to assist in prosecutions (White et al., 2018).

White et al. (2018) in this issue have improved the discussion of BWC usage in police agencies. Their research and findings will help agencies improve their BWC programs and rollouts of BWCs. Although the quality of their work provides evidence, and will help guide decisions for the policy maker, "implementer," or manager, the public and the media must understand the complexities of a BWC program. Our analogy to sports officiating, and the lack of a definitive answer to many "reviewed" calls in a controlled environment, helps us understand the limitations of BWCs during tense, uncertain, and rapidly evolving events. Time and experience will help agencies and officers get comfortable with BWCs and determine whether they are worth the costs for agencies and communities, and how they should be used and what the goal line is for measuring BWC program success. White et al. have made an important contribution, but the development and refinement of goals and evaluation criteria must continue.

\section{References}

Alexander, Ames. 2016. ACLU calls on police to release video footage of shooting. The Charlotte Observer. Sept. 21. Retrieved from charlotteobserver.com/news/local/ crime/article103183107.html.

Ariel, Barak, William A. Farrar, and Alex Sutherland. 2015. The effect of police body-worn cameras on use of force and citizens' complaints against the police: A randomized controlled trial. Journal of Quantitative Criminology 31: 509-535.

Ariel, Barak, Alex Sutherland, Darren Henstock, Josh Young, Paul Drover, Jayne Sykes, Simon Megicks, and Ryan Henderson. 2016a. Report: Increases in police use of force in the presence of body-worn cameras are driven by officer discretion: A protocol-based

4. See an interesting interactive exercise from The New York Times that shows the complexities and problems with interpreting BWC: Williams, Thomas, Jacoby, and Cave (2016). 
subgroup analysis of ten randomized experiments. Journal of Experimental Criminology, 12: 453-463.

Ariel, Barak, Alex Sutherland, Darren Henstock, Josh Young, Paul Drover, Jayne Sykes, Simon Megicks, and Ryan Henderson. 2016b. Wearing body cameras increases assaults against officers and does not reduce police use of force: Results from a global multi-site experiment. European Journal of Criminology, 13: 744-755.

Bromwich, Jonah Engel. 2016. Video of Charlotte police shooting could be the last released in North Carolina. The New York Times. Sept. 26. Retrieved from nytimes.com/2016/09/27/us/keith-scott-shooting-video-charlotte.html.

Bureau of Justice Assistance. 2015. Law Enforcement Implementation Checklist. BodyWorn Camera Toolkit. Washington, DC: Bureau of Justice Assistance. Retrieved from bja.gov/bwc/pdfs/BWCImplementationChecklist.pdf.

Bureau of Justice Assistance. 2016. BWC Policy and Implementation Program. Washington, DC: Bureau of Justice Assistance. Retrieved from bja.gov/bwc/pdfs/BWCPIPFactsheet-2016-Update-Final.pdf.

Conlin, Spencer. 2017. VT lawmakers working on statewide body camera policy. MyChamplainValley.com. Jan. 18. Retrieved from mychamplainvalley.com/news/vt-lawmakersworking-on-statewide-body-camera-policy/642350690.

Developments in the Law. 2015. Considering police body cameras. Harvard Law Review, 128: $1706-1817$.

Domonoske, Camila. 2016. 2 stories, many cameras: Protestors demand video of Charlotte shooting. NPR: The Two-Way. Sept. 22. Retrieved from nprorg/sections/thetwoway/2016/09/22/495017807/two-stories-many-cameras-protesters-demand-video-ofcharlotte-shooting.

Eiserer, Tanya. 2012. Dallas police to suspend squad-car video reviews due to officers' complaints. Dallas News. Apr. 22. Retrieved from dallasnews.com/news/news/2012/04/ 22/dallas-police-to-suspend-squad-car-video-reviews-due-to-officers-complaints.

Farrar, William A. 2013. Self-awareness to Being Watched and Socially-Desirable Behavior: A Field Experiment on the Effect of Body-Worn Cameras and Police Use-of-Force. Washington, DC: Police Foundation.

Grossmith, Lynne, Catherine Owens, Will Finn, David Mann, Tom Davies, and Laura Baika. 2015. Police, Camera, Evidence: London's Cluster Randomized Controlled Trial of Body Worn Video. London, U.K.: College of Policing Limited and the Mayor's Office for Policing and Crime.

International Association of Chiefs of Police (IACP). 2004. The Impact of Video Evidence on Modern Policing: Research and Best Practices from the IACP Study on In-Car Cameras. Alexandria, VA: IACP.

Jennings, Wesley G., Lorie A. Fridell, and Matthew D. Lynch. 2014. Cops and cameras: Officer perceptions of the use of body-worn cameras in law enforcement. Journal of Criminal Justice, 22: 549-556.

Jennings, Wesley G., Matthew D. Lynch, and Lorie A. Fridell. 2015. Evaluating the impact of police officer body-worn cameras (BWCs) on response-to-resistance and serious external complaints: Evidence from the Orlando police department (OPD) experience 
utilizing a randomized controlled experiment. Journal of Criminal Justice, 43: 480486.

Katz, Charles M., David E. Choate, Justin R. Ready, and Lidia Nuňo. 2014. Evaluating the Impact of Officer Body Worn Cameras in the Phoenix Police Department. Phoenix: Center for Violence Prevention and Community Safety, Arizona State University.

Lowery, Wesley. 2016. Charlotte officer did not activate body camera until after Keith Scott had been shot. The Washington Post. Sept. 26. Retrieved from washingtonpost.com/ news/post-nation/wp/2016/09/26/charlotte-officer-did-not-activate-body-camerauntil-after-keith-scott-had-been-shot-2/?utm_term=.87f3c2be1123.

Maskaly, Jon, Christopher Donner, Wesley G. Jennings, Barak Ariel, and Alex Sutherland. 2017. The effects of body-worn cameras (BWCs) on police and citizen outcomes: A state-of-the-art review. Policing: An International Journal, 40: 672-688.

Meyer, Robinson. 2014. Predictions about police body cameras. The Atlantic. Dec. 5. Retrieved from theatlantic.com/technology/archive/2014/12/seen-it-all-before-10predictions-about-police-body-cameras/383456/.

Police Executive Research Forum (PERF). 2014. Implementing a Body Warn Camera Program: Recommendations and Lessons Learned. Washington, DC: PERF.

Sampson, Robert J. 2010. Gold standard myths: Observations on the experimental turn in quantitative criminology. Journal of Quantitative Criminology, 26: 489-500.

Wester, Jane. 2017. Activist group files request for body camera footage in policeshooting case. The Charlotte Observer. June 12. Retrieved from charlotteobserver.com/news/local/article155702804.html.

White, Michael D. 2014. Police Officer Body-Worn Cameras: Assessing the Evidence. Washington, DC: U.S. Department of Justice, Office of Justice Programs.

White, Michael D., Janne E. Gaub, and Natalie Todak. 2017. Exploring the potential for body-worn cameras to reduce violence in police-citizen encounters. Policing. https://doi.org/10.1093/police/paw057.

White, Michael D., Natalie Todak, and Janne E. Gaub. 2018. Examining body-worn camera integration and acceptance among police officers, citizens, and external stakeholders. Criminology \& Public Policy. This issue.

Williams, Timothy, James Thomas, Samuel Jacoby, and Damien Cave. 2016. Police body cameras: What do you see? The New York Times. Apr. 1. Retrieved from nytimes.com/interactive/2016/04/01/us/police-bodycam-video.html.

Yokum, David, Anita Ravishankar, and Alexander Coppock. 2017. Evaluating the Effects of Police Body-Worn Cameras: A Randomized Controlled Trial. Washington, DC: The Lab @ DC, Office of the City Administrator, Executive Office of the Mayor.

\section{Statute Cited}

South Carolina Code of Laws $\$ 23-1-240$ (2017).

Geoffrey P. Alpert is a professor of criminology and criminal justice at the University of South Carolina and holds an appointment at Griffith University. He is also a chief research 
advisor for NIJ. He has taught at the FBI National Academy, the Federal Law Enforcement Training Center, and The Senior Management Institute for Police and is currently a Federal Monitor for the New Orleans Police Department and on the compliance team for the Portland, Oregon Police Bureau. He testified to the President's Task Force on 21st Century Policing, and is a member of the International Association of Chiefs of Police Research Advisory Committee and Policy Center Advisory Group. For the past thirty years, his research interests have included police use of force, emergency driving, and the linkages between researchers and practitioners.

Kyle McLean recently completed his Ph.D. in criminology and criminal justice at the University of South Carolina. He will be joining the faculty at Florida State University in August 2018. His research interests are in policing, criminological theory, and social psychology. His recent research has appeared in Criminal Justice and Behavior, The British Journal of Criminology, Crime \& Delinquency, and Police Quarterly. 